\title{
ANTIHYPERTENSIVE PHARMACOTHERAPY IN HYPERTENSIVE PATIENTS AT A TERTIARY CARE TEACHING HOSPITAL AND MEDICAL COLLEGE IN INDIA
}

\author{
RANJODH JEET SINGH* \\ Department of Pharmacology, Maharishi Markandeshwar Institute of Medical Sciences and Research, Maharishi Markandeshwar Deemed \\ to be University, Mullana, Haryana, India. Email: ranjotsmith1986@gmail.com
}

Received: 14 July 2021, Revised and Accepted: 11 September 2021

\begin{abstract}
Objectives: The aim of the study was to compare the efficacy of Atenolol and Olmesartan in Stage- 1 hypertension (HTN), and the adverse effect profile of Atenolol and Olmesartan in Stage-1 HTN.

Methods: A prospective, randomized, open, and parallel study was carried out in 100 patients attending the outpatient department of General Medicine Department MMIMSR, Mullana, Ambala, India with Stage -1 HTN according to joint national committee VII. The patients were randomly divided into two groups to receive Tab. Atenolol $50 \mathrm{mg}$ od (Group A, n=50) and Tab. Olmesartan medoxomil $20 \mathrm{mg}$ (Group B, n=50) od for a total period of 12 weeks with regular follow up every 2 weeks from the baseline. At each visit, blood pressure (BP), heart rate, and adverse effects were evaluated. Laboratory investigations were carried out at baseline and end of the study period. $\mathrm{p}<0.005$ was considered statistically significant.
\end{abstract}

Results: Atenolol and Olmesartan medoxomil both significantly reduce BP and heart rate $(\mathrm{p}<0.005)$. Olmesartan medoxomil is more efficacious in reducing $\mathrm{BP}$

Conclusion: Olmesartan medoxomil is a better choice for Stage -1 HTN between the two drugs as it leads to a greater decrement in BP

Keywords: Cardiovascular disease, Hypertension, Blood pressure, Systolic blood pressure, Diastolic blood pressure, Beta-blockers, Angiotensin receptor blockers, Heart rate.

(C) 2021 The Authors. Published by Innovare Academic Sciences Pvt Ltd. This is an open access article under the CC BY license (http://creativecommons.org/ licenses/by/4.0/) DOI: http://dx.doi.org/10.22159/ajpcr.2021v14i11.42728. Journal homepage: https://innovareacademics.in/journals/index.php/ajpcr

\section{INTRODUCTION}

Cardiovascular disease (CVD) is one of the most common contributors of morbidity and mortality in underdeveloped and developing countries including South Asian countries including India [1]. The emergence of the CVD epidemic during the last three to four decades has been a very concerning cause for health-care providers in recent years [2]. Among the cluster group of CVDs, hypertension (HTN) represents the most common form of cardiovascular risk factor [3]. Several previous studies have demonstrated longitudinal associations between HTN and coronary artery disease, myocardial infarction [4]. HTN is defined as blood pressure (BP) of $140 / 90 \mathrm{mmHg}$ or more on two separate occasions measured at least 1-2 weeks apart [5]. The prevalence of HTN increases with advancing age [5]. It affects approximately onethird of the world's adult population and it is predicted to increase by $60 \%$ toward 2025 [6]. HTN is also associated with several serious conditions and accounts for $13.5 \%$ of all premature deaths, $54 \%$ of all strokes, and $47 \%$ of ischemic heart diseases [7]. The number of adults with HTN in 2025 is predicted to exponentially increase by about $60 \%$ to a total of 1.56 billion [8]. Among all the hypertensive populations in developed countries and India, the percentage of those who are adequately controlled is estimated to be $50 \%$ and $11-12.8 \%$, respectively [9]. CVDs caused 2.3 million deaths in India in the year 1990; this is expected to double by the year 2020 [10]. HTN can be simply described as abnormal elevation in BP [11]. Primary HTN - with no obvious underlying medical causes [12] and secondary HTN - with identifiable cause [5]. According to joint national committee (JNC) VII in 2003, an increase in BP was again classified into three stages of HTN [5]. The JNC 8 classification for HTN and guideline management algorithm has been recently released in 2014 [13]. Another subtype of HTN includes isolated systolic HTN defined as a wide pulse pressure HTN resulting from excessive large artery stiffness [14]. Numerous common genetic variants with small effects on BP have been identified, for example, GUCY1A3-GUCY1B3 [15]. Several risk factors have been identified for the development of Primary or Essential HTN $[16,17]$. Diet: Micronutrients correlate with the prevalence of HTN and salt intake [18]. Inadequate intake of potassium, calcium, and magnesium has been implicated in the risk of HTN in various populations study but not in all trials $[19,20]$. Hyperlipidemia: Low high-density lipoprotein cholesterol and increased triglycerides are predictors of coronary artery heart diseases [21]. Obesity: $50 \%$ of obese patients have concomitant HTN [22] visceral obesity a strong risk factor for HTN [23-25]. The relationship between obesity and HTN is observed virtually in all societies, ages [26]. Smoking: Smoking is an independent risk factor for cardiovascular deaths and stroke in females where risk is doubled [27]. Genetics: Genes have been implicated in the causation of high BP $[28,29]$. Aging: It has been found that BP increases with age, especially systolic BP (SBP) [30]. Type A personality: It has been well proven that type A personality has an increased risk of atherosclerosis and coronary morbidity [31]. Newer risk factors: Fibrinogen, hyperhomocysteinemia are new emerging factors of HTN [32-35]. About 30\% of populations with hyperhomocysteinemia were found to have premature atherosclerosis [36]. Secondary HTN results from an identifiable underlying cause [37,38]. In most people with high BP, increased resistance to blood flow contributes to an elevation in BP level while heart rate remains normal [39]. Most evident implicates abnormalities in the intrarenal renin-Angiotensinaldosterone system [40,41]. Korotkoff described the systolic and diastolic sounds he heard with a stethoscope [42]. Janeway abandoned the clinical use of the term: essential HTN and called the disorder: hypertensive CVD [43]. Southern Medical Journal stated that: HTN is neither a cause of nephritis or arteriosclerosis [44]. The treatment of HTN itself is a difficult [45]. In 1950 despite the advances that occurred with the availability of Reserpine, Ganglionic blocking agents, limited the effectiveness [46]. Lowering BP in patients with HTN significantly decreased cardiovascular morbidity and mortality as compared with a 
placebo-controlled trial [47]. The first JNC report was issued in 1977 with updates occurring every 4-5 years [48]. In 2003, the JNC 7 report modified the previous JNC 6 guidelines and recommends a thiazidetype diuretic as the preferred choice for initial monotherapy [49]. Lifestyle modifications complement to pharmacological therapy in lowering BP [50]. Diet control measures: The Diet Approach to Stop HTN trial showed a reduction in BP of $11.4 / 5.5 \mathrm{~mm} \mathrm{Hg}$ [51]. Salt: There was a decrease of $4.8 / 2.5 \mathrm{mmhg}$ in hypertensive patients $[52,53]$. Potassium: Potassium protects against vascular disease [54]. Calcium: The same inverse relationship has been shown with magnesium intake [55]. Calories and fat: Diets with fewer calories cause reductions in BP [56]. Alcohol: More than 3 drinks per day is a predictive cause for HTN [57]. Smoking: Smoking cessation decreases the risk of coronary artery [58]. Exercise: Sedentary individuals with normal BP have a $20-50 \%$ increased risk of developing HTN [59]. Various drugs are available for treatment of HTN. Clinical trials have shown that thiazides in combination with other drugs have a synergistic effect $[60,61]$. The veteran's affairs cooperative study class on antihypertensive agents has shown that the overall response rate in no responders was increased to $65 \%$ from $49 \%$ when combination therapy was used [62]. Betablockers: Propranolol it revolutionized the medical management [63]. Atenolol is widely used for the management of HTN [64]. Angiotensin receptor blockers: All drugs in this class are approved by Food and Drug Administration for treatment of HTN, either alone or in combination with other drugs [65]. Olmesartan is a comparatively new Angiotensin II receptor antagonist used to treat HTN.

\section{METHODS}

A prospective, randomized, open, and parallel study was carried out in 100 patients attending the outpatient department of General Medicine Department MMIMSR, Mullana, Ambala, India with Stage-1 HTN. The patients were randomly divided into two groups to receive Tab. Atenolol $50 \mathrm{mg}$ od (Group A, $\mathrm{n}=50$ ) and Tab. Olmesartan medoxomil $20 \mathrm{mg}$ (Group B, n=50) od for a total period of 12 weeks with regular follow-up every 2 weeks from the baseline.

\section{RESULTS}

Results were recorded and compared from the baseline. The results of the BP of individual patients were consolidated at the end of 12 weeks after treatment for both groups.

The analysis of Fig. 1 showed the average age of the patients treated with Atenolol $50 \mathrm{mg}$ Drug was $43.10 \pm 7.78$ years which was not significantly $p>0.05$ different than the average age of the patients treated under the Olmesartan $20 \mathrm{mg}$ Drug, that is, $42.86 \pm 9.23$. In the research study overall, 27-60 years of patients were considered and among them, 28-60 years of patients were receiving the Atenolol $50 \mathrm{mg}$ Drug, and the patients in the age group of 27-60 years were receiving Olmesartan 20 mg Drug.

There were no statistical differences in context with baseline age characteristics between the two groups. The parameters were normally distributed and comparable ( $\mathrm{p}$-value>0.05).

The analysis of Fig. 2 showed in the research study $58.0 \%$ (58) were males and among them, $31(62 \%)$ were receiving the Atenolol $50 \mathrm{mg}$ Drug treatment, and 27 (54.0\%) were receiving the Olmesartan $20 \mathrm{mg}$ drug treatment. Furthermore, there were $42.0 \%$ (42) of females were involved in the study and among them, 19 (38.0\%) were receiving the Atenolol $50 \mathrm{mg}$ drug treatment, and 23 (26.0\%) were receiving the Olmesartan $20 \mathrm{mg}$ drug treatment. The p-value obtained was $>0.05$ which shows that there is no significant difference in gender distribution of the two study groups.

The baseline means SBP of subjects in the Atenolol $50 \mathrm{mg}$ drug group was 148.60 which significantly drops down to 143.12 at week 2 assessment followed by again significant drops at each 2-week assessment and finally by the end of the 12 -week assessment it significantly drops to 137.36 . The baseline means SBP of subjects in the Olmesartan $20 \mathrm{mg}$ drug group was 148.12 which significantly drops down to 138.28 at week 2 assessment followed by again significant drops at each 2-week assessment and finally by the end of the 12 -week assessment it significantly dropped to 128.88 .

It was further assessed that at baseline no significant difference was recorded among SBP levels among subjects of both drug groups but on comparative analysis at each week assessment shows that the

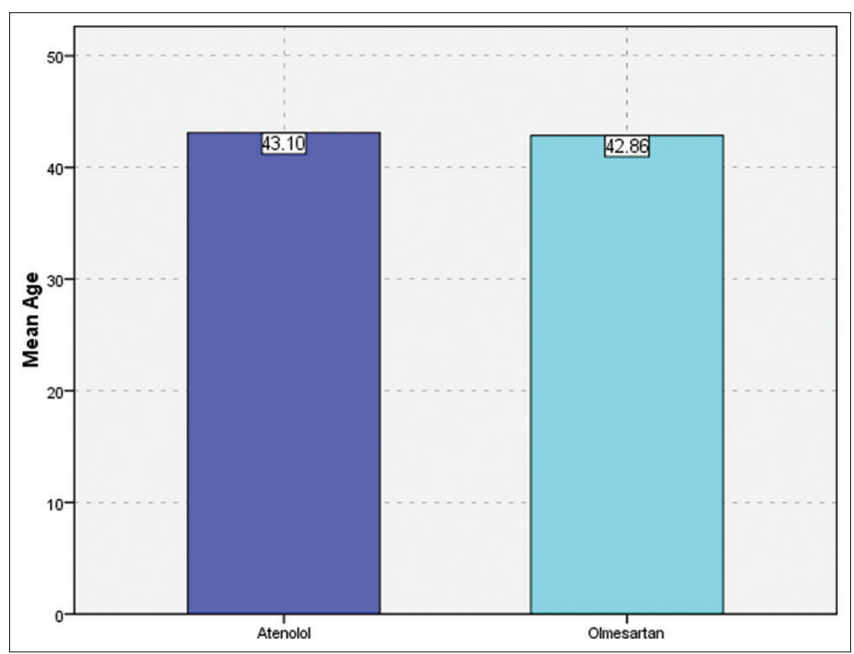

Fig. 1: Comparison of the mean age of Group A and Group B

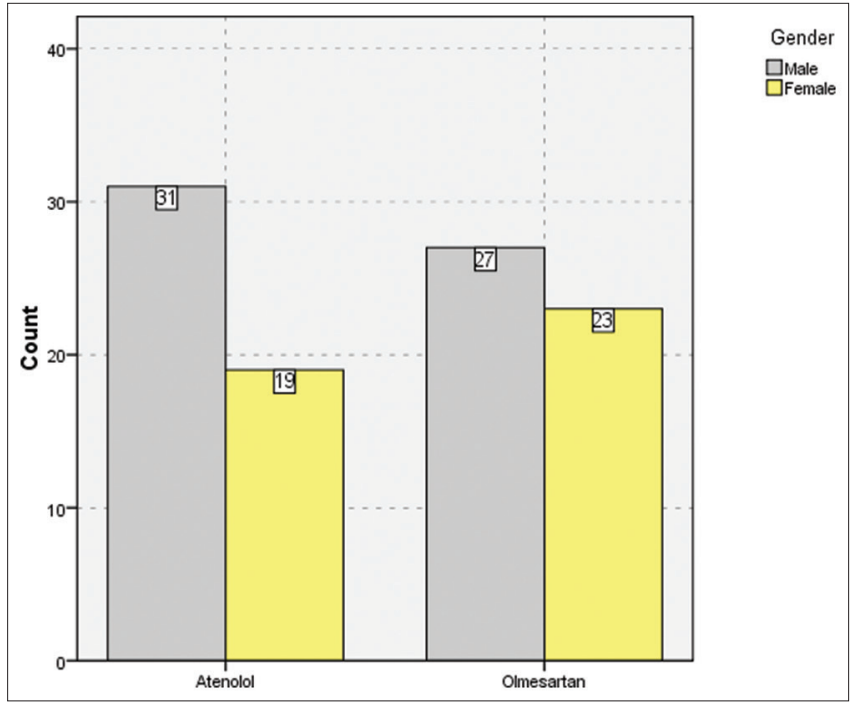

Fig. 2: Gender Distribution of Subjects under Group A and Group B

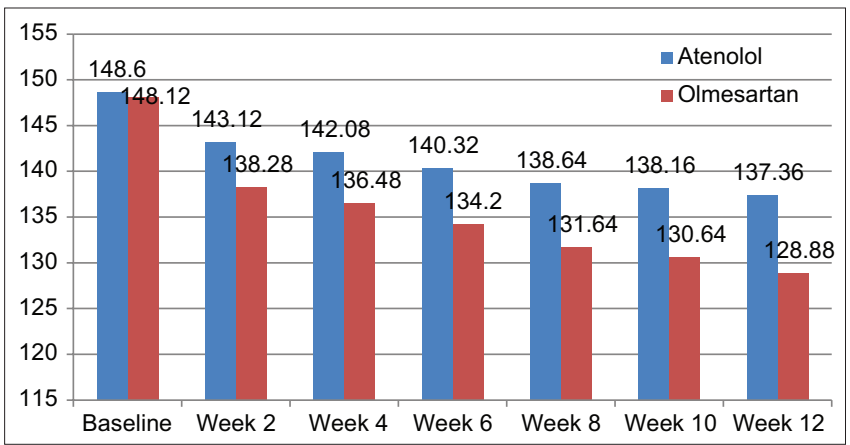

Fig. 3: Comparison of Systolic Blood Pressure in Group A and Group B 
subjects of Olmesartan $20 \mathrm{mg}$ groups showed more decrease in SBP as compared to Atenolol $50 \mathrm{mg}$ group subjects at baseline both subjects group Atenolol $50 \mathrm{mg}$ and Olmesartan $20 \mathrm{mg}$ had an average SBP of 148.60 and 148.12 , respectively, whereas at $12^{\text {th }}$-week assessment there was significant difference recorded as values of 137.36 and 128.88 , respectively.

The analysis of Fig. 4 showed that the overall reduction in SBP was more among the subjects under the drug group Olmesartan $20 \mathrm{mg}$, that is, $13.0 \%$ in the $12^{\text {th }}$ week since the baseline recordings in comparison to the reduction in the same period for the subjects under the drug group Atenolol $50 \mathrm{mg}$, that is, $7.6 \%$. Furthermore, it was analyzed that at each week's assessment the percentage drop of SBP was evident more among the Olmesartan $20 \mathrm{mg}$ group subjects in comparison to Atenolol $50 \mathrm{mg}$ subjects.

The baseline means diastolic BP (DBP) of subjects in the Atenolol $50 \mathrm{mg}$ drug group was 94.92 which significantly drops down to 91.68 at week 2 assessment followed by a non-significant drop to 91.44 at the $4^{\text {th }}$ week assessment of subjects but after that, at each 2-week assessment there was significant drop was recorded and finally, by the end of the 12-week assessment it significantly dropped to 87.08.

The baseline mean DBP of subjects in the Olmesartan 20 mg drug group was 94.08 which significantly drops down to 88.04 at week 2 assessment and after that at each 2-week assessment there was significant drop was recorded and finally, by the end of the 12-week assessment, it significantly dropped to 81.24. It was further assessed that at baseline no significant difference was recorded among the DBP levels among the subjects of both drug groups but on comparative analysis at each week, the assessment shows that the subjects of Olmesartan $20 \mathrm{mg}$ groups showed more decrease in DBP as compared to Atenolol $50 \mathrm{mg}$ group subjects at baseline both subjects under group Atenolol $50 \mathrm{mg}$ and Olmesartan $20 \mathrm{mg}$ had average DBP of 94.92 and 94.08, respectively, whereas at $12^{\text {th }}$-week assessment there was significant difference recorded as values of 87.08 and 81.24 , respectively.

The analysis of Fig. 5 showed that the overall reduction in DBP was more among the subjects under the drug group Olmesartan, that is,

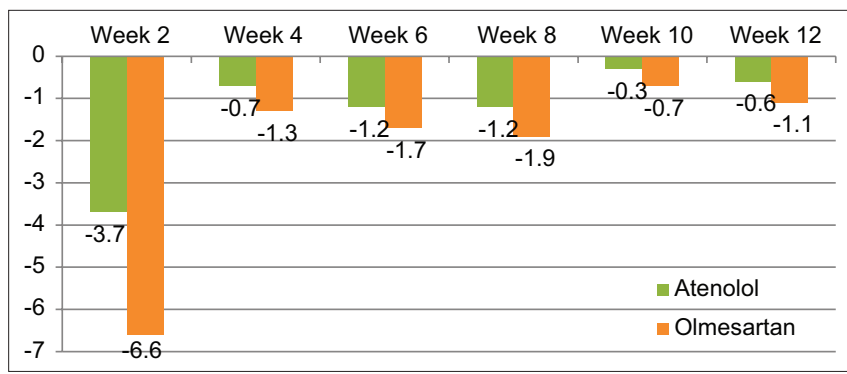

Fig. 4: Comparison of Percentage Reduction in Systolic Blood Pressure of Group A and Group B

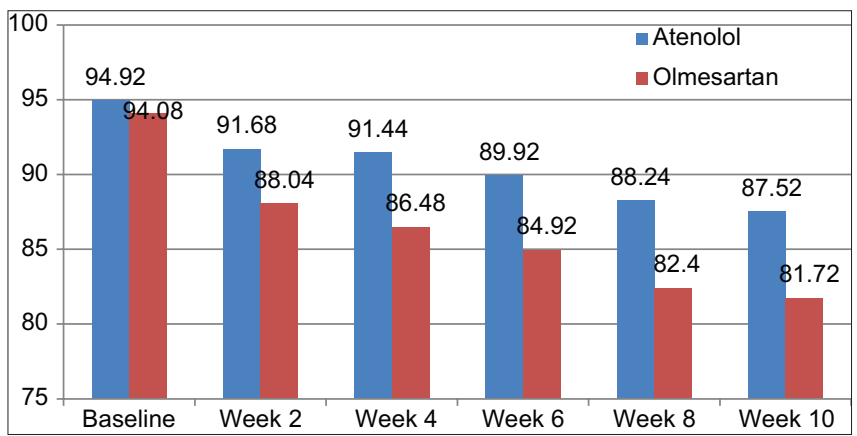

Fig. 5: Comparison of Diastolic Blood Pressure in Group A and Group B
$13.6 \%$ in the $12^{\text {th }}$ week since the baseline recordings in comparison to the reduction in the same period for the subjects under the drug group Atenolol, that is, $8.3 \%$. It was analyzed at most of the week assessment the percentage drop of DBP was almost similar among both drug groups, that is, weeks 6,10 , and 12 assessment whereas the larger difference was recorded at rest 3-week assessments.

The baseline means heart rate of subjects in the Atenolol $50 \mathrm{mg}$ drug group was 85.72 which significantly drops down to 83.48 at week 2 assessment followed by a significant drop at each 2-week assessment and finally by the end of the 12 -week assessment it significantly dropped to 72.64

The baseline means heart rate of subjects in Olmesartan $20 \mathrm{mg}$ drug group was 86.72 which significantly drops down to 81.48 at week 6 assessment but at $8^{\text {th }}$-week assessment, it was not significant drop, that is, 81.36 but after that, at each 2-week assessment there was significant drop was recorded and finally, by the end of the 12-week assessment, it significantly dropped to 78.88 .

It was further assessed that at baseline no significant difference was recorded among the heart rate levels among the subjects of both drug groups as the subjects of Olmesartan $20 \mathrm{mg}$ had a higher heart rate average than the subjects of Atenolol $50 \mathrm{mg}$ subjects and on comparative analysis at each week assessment shows that the subjects of Olmesartan groups showed a lesser decrease in heart rate as compared to Atenolol $50 \mathrm{mg}$ group subjects at baseline both subjects group Atenolol $50 \mathrm{mg}$ and Olmesartan $20 \mathrm{mg}$ had average heart rate of 85.72 and 86.72 respectively whereas at $12^{\text {th }}$-week assessment there was significant difference recorded as values of 72.64 and 78.88 , respectively.

The analysis of Fig. 7 showed that the overall reduction in heart rate was more among the subjects under the drug group Atenolol $50 \mathrm{mg}$, that is, $15.3 \%$ in the $12^{\text {th }}$ week since the baseline recordings in comparison to the reduction in the same period for the subjects under the drug

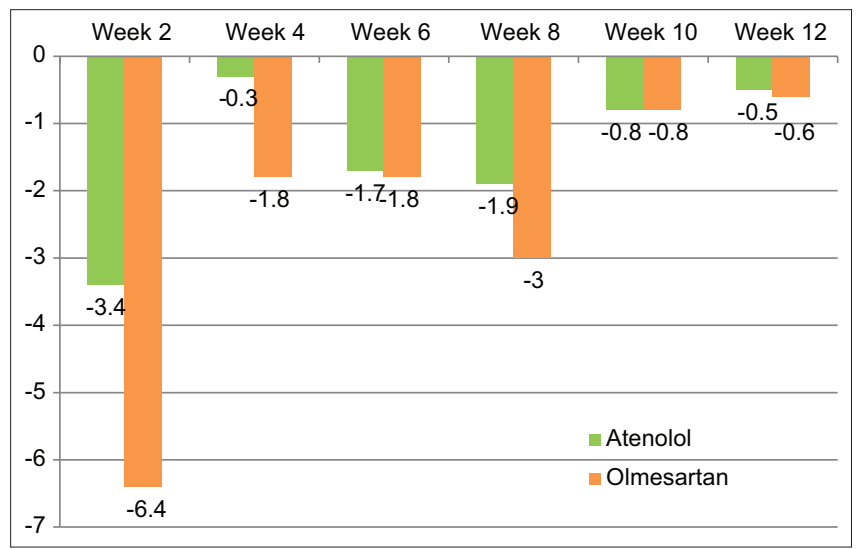

Fig. 6: Comparison of Percentage Reduction in Diastolic Blood Pressure of Group A and Group B

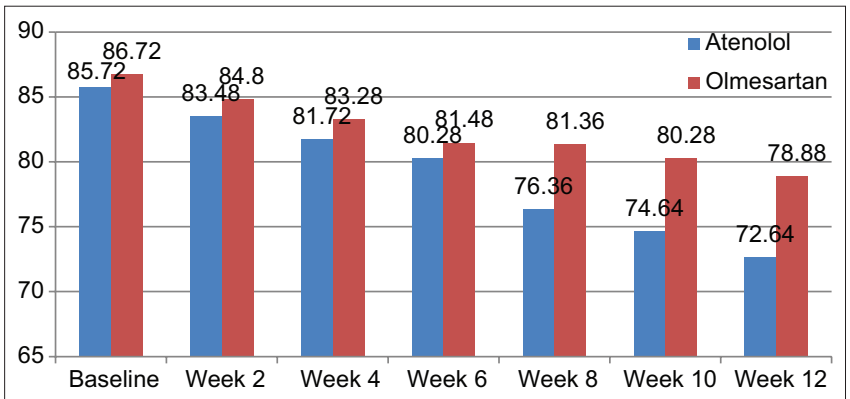

Fig. 7: Comparison of Heart Rate in Group A and Group B 
group Olmesartan $20 \mathrm{mg}$, that is, $9.0 \%$. It was analyzed at all of the week assessment the percentage drop of heart rate was more among the Atenolol $50 \mathrm{mg}$ group subjects but the opposite trend was only evident at $6^{\text {th }}$-week assessment when the subjects from the Olmesartan $20 \mathrm{mg}$ showed more decrease in heart rate than the subjects from the Atenolol $50 \mathrm{mg}$ group.

The subjects of the Atenolol $50 \mathrm{mg}$ group their average fasting blood sugar level at baseline time was 104.1 which decreased to 92.0 at the $12^{\text {th }}$ week of assessment whereas among the subject of the Olmesartan $20 \mathrm{mg}$ group their average fasting blood sugar level at baseline was 105.6 but it drops down to 91.6 at the $12^{\text {th }}$-week assessment

In the comparison of the two groups for the fasting blood sugar level, there was no significant difference was recorded at baseline and $12^{\text {th }}$ week between the fasting blood sugar of subjects measured. It was concluded that among the subjects of the Atenolol $50 \mathrm{mg}$ group their fasting blood sugar level decreased by $-8.9 \%$ from baseline to $12^{\text {th }}$ week assessment while among the subjects of the Olmesartan $20 \mathrm{mg}$ group it decreased by $9.0 \%$ in a similar time frame.

Fig. 9 describes the distribution of the subjects in terms of the adverse effect of drugs and it was analyzed that the neurological symptoms in Group A, 32.0\% and 26.0\% subjects reported headache and dizziness, respectively, while $16.0 \%$ and $36.0 \%$ of subjects reported the same in Group B, respectively.

\section{DISCUSSION}

Regarding baseline characteristics such as age distribution, there was no statistical difference $(p>0.05)$ between the two groups. The Mean Age for Group A patients were43.10 \pm 7.78 years and Group B patients were $42.86 \pm 9.23$ years, respectively. The age group selected for our study was $18-60$ years. A similar age group was taken by Jackson

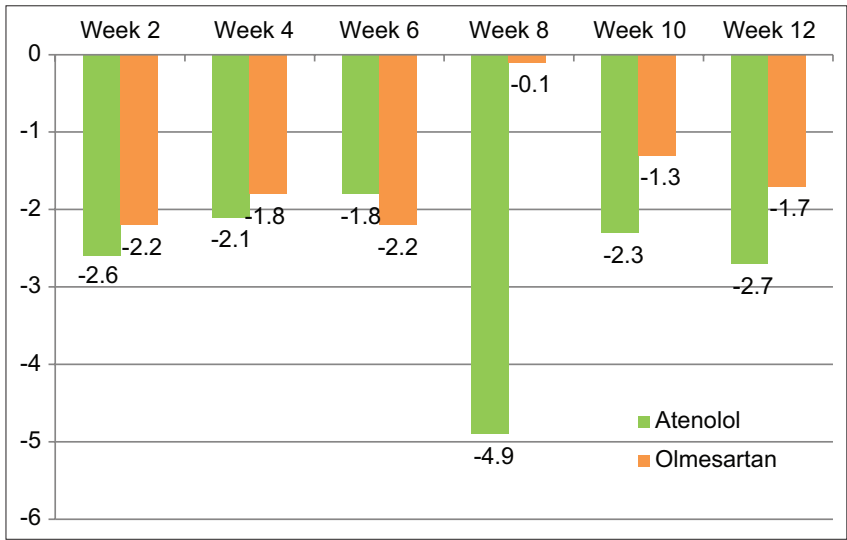

Fig. 8: Comparison of percentage difference in heart rate in Group A and Group B

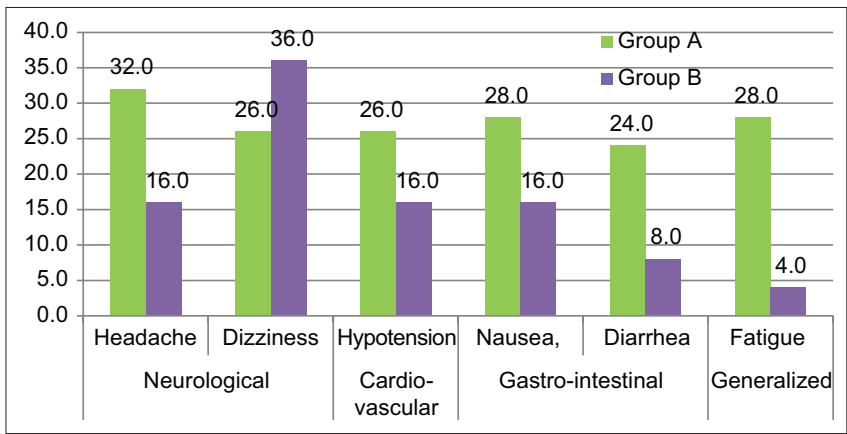

Fig. 9: Bar Chart Comparison of adverse drug reactions among both Drug Group Subjects under Atenolol $50 \mathrm{mg}$ and Olmesartan 20 mg Drug Treatment et al. to see the effect of antihypertensive drugs (Atenolol, Ramipril, and Amlodipine) on lowering BP in hypertensive patients of age group 18-70 years for 3 years and no statistical difference $(p>0.05)$ between two groups regarding age distribution [66]

While comparing other baseline characteristics such as gender distribution, the p-value obtained was $>0.05$ which shows that there is no significant difference in gender distribution of the two study groups. In our study, there were 31 males and 19 females in Group A and under the Group B category, there were 27 males and 23 females. In a study conducted by Rasmussen et al.. thirteen patients, of which nine men and four women were enrolled to do a comparison between effects of Atenolol and Metoprolol on BP and heart rate at rest, during exercise and there was no statistical difference $(p>0.05)$ between two groups in context with gender distribution [67].

The parameters of our study were normally distributed and were comparable. One of the parameters of observations was SBP. The baseline means SBP of subjects in the Atenolol drug group was 148.60 which significantly drops down to 143.12 at week 2 assessment followed by again significant drops at each 2 -week assessment and finally by the end of the 12-week assessment it significantly drops to 137.36 an average reduction of $11.24 \mathrm{mmHg}$, while Freytag et al.. conducted a study to compare the efficacy as well as tolerability of Atenolol and Telmisartan in treatment of mild to moderate type of HTN in 489 patients for 26 weeks, they concluded that Final SBP reductions of $16.7 \mathrm{mmHg}$ for the Atenolol, the difference in SBP was significant $(p<0.005)$. When we compared the results of these studies, we found that there is a greater reduction of SBP, that is, $16.7 \mathrm{mmHg}$ in Freytag et al.. than our study, that is, $11.24 \mathrm{mmHg}$ [68].

The baseline means SBP of subjects in the Olmesartan drug group was 148.12 which significantly drops down to 138.28 at week 2 assessment followed by again significant drops at each 2-week assessment and finally by the end of the 12-week assessment it significantly dropped to 128.88 , that is, an average reduction of $19.24 \mathrm{mmHg}$. A similar double-blind study was conducted by Van Miegham to compare the efficacy of Olmesartan $20 \mathrm{mg}(\mathrm{n}=165)$ and Atenolol $50 \mathrm{mg}(\mathrm{n}=161)$ for 12 weeks. They concluded that a significantly greater reduction in SBP was observed from baseline with Olmesartan $(-20.7 \pm 1.0)$ than with Atenolol $(-17.2 \pm 1.0)$. When we compared the results of these studies, we found that a reduction of $20.7 \mathrm{mmHg}$ of SBP was observed in the Van Miegham study, while a reduction of $19.24 \mathrm{mmHg}$ was observed in our study, and results are almost coinciding with each other [69].

The baseline means DBP of subjects in the Atenolol drug group was 94.92 which significantly drops down to 91.68 at week 2 assessment followed by a non-significant drop to 91.44 at the $4^{\text {th }}$-week assessment of subjects but after that, at each 2-week assessment there was a significant drop was recorded and finally, by the end of the 12 -week assessment it significantly dropped to 87.08 , thus there is a significant decrease of $7.84 \mathrm{mmHg}(\mathrm{p}<0.001)$. Alcocer et al.. conducted an openlabel, parallel-group comparative study to analyze the clinical efficacy and safety of Atenolol $50 \mathrm{mg}$ and Telmisartan $80 \mathrm{mg}$ on systolic and DBP in 58 patients with mild to moderate HTN and concluded that there was a significant decrease in DBP of $10.1 \mathrm{mmHg}$ versus $14.7 \mathrm{mmHg}$. When we compared the results of these studies, we found that greater reduction of DBP, that is, $10.1 \mathrm{mmHg}$ in the Alcocer et al.. study than our study, that is, $7.84 \mathrm{mmHg}[70]$.

The baseline mean DBP of subjects in the Olmesartan drug group was 94.08 which significantly drops down to 88.04 at week 2 assessment and after that, at each 2 -week assessment there was significant drop was recorded and finally, by the end of the 12-week assessment, it significantly drops to 81.24 , thus there is the final reduction of $12.84 \mathrm{mmHg}$. Puchler et al. conducted a double-blind study on 328 patients with moderate to severe type HTN mean sitting DBP of 100 to $120 \mathrm{mmHg}$ receiving $25 \mathrm{mg}$ of hydrochlorothiazide daily randomly assigned to receive either Olmesartan $(10 \mathrm{mg})$ once daily 
plus HCTZ or Atenolol $(50 \mathrm{mg}$ ) once daily plus HCTZ for 12 weeks and they concluded that mean reduction in DBP from the baseline were similar for Olmesartan group $(-17.3 \pm 6.3 \mathrm{mmhg})$ and the Atenolol group $(-17.2 \pm 6.4 \mathrm{mmHg})$ in patients receiving either Olmesartan $(10 \mathrm{mg})$ once daily plus HCTZ or Atenolol (50 mg) once daily plus HCTZ for 12 weeks. When we compared the results of these studies, we found that there is a reduction of $17.3 \mathrm{mmHg}$ of DBP in the Puchler et al.. study while there is a lesser reduction of DBP, that is, $12.84 \mathrm{mmHg}$ in our study. The greater reduction may be due to the addition of HCTZ as an antihypertensive drug in this study [71].

The heart rates in Group A (Atenolol). The baseline means heart rate of subjects in the Atenolol drug group was 85.72 which significantly drops down to 83.48 at week 2 assessment followed by a significant drop at each 2-week assessment and finally by the end of the 12-week assessment it significantly dropped to 72.64 , counting for an average reduction of 13.08 beats $/ \mathrm{min}$. While Pollare et al.. conducted a study on sixty patients with primary HTN and studied the effects of Atenolol and Metoprolol and concluded that there is a significant reduction in heart rate, 9 beats/min in the supine position after medication, which was similar for Atenolol and Metoprolol. When we compared the results of these studies, we found that heart rate was decreased significantly in both of these studies but a greater reduction in heart rate was observed in our study, that is, 13.08 beats/min as compared to 9 beats $/ \mathrm{min}$ in Pollare et al.. study [72].

In Group B (Olmesartan), the baseline means Heart Rate of subjects in the Olmesartan drug group was 86.72 which significantly drops down to 81.48 at week 6 assessment but at $8^{\text {th }}$ week assessment, it was not significant drop, that is, 81.36 but after that, at each 2-week assessment there was significant drop was recorded and finally, by the end of the 12-week assessment, it was significant drops to 78.88, that is, an average reduction of 7.8 beats $/ \mathrm{min}$. A fine comparative study conducted by Rasmussen et al.. on 13 patients (nine men and four women, aged 37-67 years) with mild/moderate essential HTN to do a comparison between Atenolol and Metoprolol 50, 100, and $200 \mathrm{mg}$ doses given once daily on BP, and concluded that significant $(p<0.001)$ reduction of 12 beats/min in heart rate in test situations were observed with $50 \mathrm{mg}$ Atenolol [67]. While Sahana et al.. studied the effect of-Atenolol $50 \mathrm{mg}$ once daily versus Nebivolol $5 \mathrm{mg}$ once daily $(\mathrm{S})$ in patients with essential HTN and concluded that fall in heart rate was significant $(\mathrm{p}<0.0001)$ by 11 beats $/ \mathrm{min}$ at the end of the $1^{\text {st }}, 2^{\text {nd }}$, and $3^{\text {rd }}$ month when compared to baseline by Atenolol $50 \mathrm{mg}$ therapy. When we compared our results with these studies we concluded that although Olmesartan is reducing heart significantly by 7.8 beats $/ \mathrm{min}$ Atenolol is found to be more significantly reducing the heart rate by 12 beats/min in Rasmussen et al.. study and 11 beats/min in Sahana et al.. studies $[67,73]$.

Fasting blood sugar level among Group A (Atenolol) patients at baseline was $104.1 \pm 14.2 \mathrm{mg} / \mathrm{dl}$ which non-significantly decreased to $92.0 \pm 12.9 \mathrm{mg} / \mathrm{dl}$, that is, it reduces by $8.9 \%$. In Group B, (Olmesartan) subject's baseline Fasting blood sugar level was observed to be $105.6 \pm 15.3 \mathrm{mg} / \mathrm{dl}$ which non significantly reduces by $9.0 \%$ to $91.6 \pm 13.0 \mathrm{mg} / \mathrm{dl}$ at the end of 12 weeks of therapy. Fonseca reviewed the pathophysiology of HTN and evaluated the effects from glucose by beta-blockers, namely, Atenolol, Metoprolol, Propranolol and concluded that beta-blockers have favorable effects on glucose metabolism [74]. This study is coinciding with my study. Smith et al.. evaluated Atenolol effects in men with type 2 diabetes mellitus during cardio respiratory exercise in both fasting and postprandial glucose and demonstrates that Atenolol decreased fasting and postprandial glucose $(p<0.001)$. This study differs from my study, thus to confirm effects on fasting blood sugar, more studies are to be done [75].

During treatment, adverse effects were reported by the patients of both Groups. It was analyzed that the neurological symptoms headache and dizziness in Group A are $32.0 \%$ and $26.0 \%$ in subjects, respectively, while $16.0 \%$ and $36.0 \%$ in subjects in Group B, respectively. Gastrointestinal symptoms nausea, vomiting, and diarrhea reported in Group A are $28.0 \%$ and $24.0 \%$ in subjects, respectively, while $16.0 \%$ and $8.0 \%$ in subjects reported the same in Group B, respectively.

About $26.0 \%$ of subjects in Group A reported hypotension while $28.0 \%$ reported fatigue on contrary in Group B $16.0 \%$ of subjects reported hypotension and $4.0 \%$ reported fatigue. Van Miegham conducted a double-blind study on 326 patients who are randomly assigned to receive either Olmesartan $20 \mathrm{mg}$ once daily or Atenolol once daily for 12 weeks and concluded that both Olmesartan and Atenolol were well tolerated and adverse effects reported were minimal and were nonsignificant ( $p>0.001)$. Thus, in terms of adverse effects, my study is coinciding with this study [69]

\section{CONCLUSION}

Olmesartan is a better choice for the treatment of Stage I hypertensive patients because of a greater reduction in BP. The lesser decrement of heart rate with Olmesartan indicates its preferred use in end-organ failure clinical conditions. The fewer incidences of adverse events with Olmesartan than Atenolol indicate a better safety profile.

\section{ACKNOWLEDGMENT}

The authors want to acknowledge the Maharishi Markandeshwar Institute of Medical Sciences and Research, a constituent unit of Maharishi Markandeshwar deemed to be university, Mullana, Ambala, and Haryana, India, for giving the platform to conduct this study. The author also wants to acknowledge with the special note of thanks to the patients for participation in this study.

\section{AUTHOR CONTRIBUTION}

The author conducted the study, collected, and processed the prescriptions and performed the analysis in detail with requisite procedures including statistical analysis, and further interpreted the data and prepared the manuscript.

\section{CONFLICT OF INTEREST}

None declared.

\section{AUTHOR FUNDING}

Nil.

\section{REFERENCES}

1. Elkum N, Al-Arouj M, Sharifi M, Behbehani K, Bennakhi A. Cardiovascular disease risk factors in the South Asian population: A cross-sectional study. Diabet Med 2014;31:531-9.

2. Ismail J, Jafar TH, Jafary FH, White F, Faruqui AM, Chaturvedi N. Risk factors for non-fatal myocardial infarction in young South Asian adults. Heart 2004;90:259-63.

3. Gupta R, Misra A, Vikram NK, Kondal D, Gupta SS, Agrawal A, et al. Younger age of escalation of cardiovascular risk factors in Asian Indian subjects. BMC Cardiovase Disord 2009;9:28.

4. Stafylas PC, Sarafidis PA. Carvedilol in hypertension treatment. Vasc Health Risk Manag 2008;4:23-30.

5. Chobanian AV, Bakris GL, Black HR, Cushman WC, Green LA, Izzo JL, et al. Seventh report of the joint national committee on prevention, detection, evaluation, and treatment of high blood pressure: The JNC report. JAMA 2003;289:2560-72.

6. Bundgaard M, Jarbol DE, Paulsen MS, Jacobsen JL, Pedersen ML. Prevalence of the use of antihypertensive medications in Greenland: A study of quality of care amongst patients treated with antihypertensive drugs. Int J Circumpolar Health 2012;71:103402.

7. Lawes CM, Hoorn VS, Rodgers A. Global burden of blood-pressurerelated disease, 2001. Lancet 2008;371:1513-28.

8. Patricia MK, Megan BS, Kristi R, Paul M, Paul KW, Jiang H. Global burden of hypertension: Analysis of worldwide data. Lancet 2005;365:217-23.

9. Thakur K, Malhotra P, Walia T, Kumar R. Health awareness and treatment compliance of high blood pressure among women in periurban 
colony of Chandigarh, India. Indian Med Assoc 1999;97:217-9.

10. Gupta R. Trends in hypertension epidemiology in India. J Hum Hypertens 2004;18:73-8.

11. Hamon M, Loncew DA. Overview of circulation; medical, physics of pressure flow and resistance. In: Guyton Medical Physiology Editors, Guyton and John Hall. 12 th ed. Philadelphia, PA: Elsevier; 2011. p. 166.

12. Carretero OA, Oparil S. Essential hypertension. Part I: Definition and etiology. Circulation 2000;101:329-35.

13. James PA, Oparil S, Carter BL, Cushman WC, Dennison C. Report from the panel members appointed to the eighth joint national committee (JNC 8). JAMA 2014;311:507-20.

14. Franklin SS. Is there a preferred antihypertensive therapy for isolated systolic hypertension and reduced arterial compliance. Curr Hypertens Rep 2000;2:253-59.

15. Ehret GB, Munroe PB, Rice KM, Bochud M, Johnson AD, Chasman DI, et al.. Genetic variants in novel pathways influence blood pressure and cardiovascular disease risk. Nature 2011;478:103-9.

16. Haslam DW, James WP. Obesity. Lancet 2005;366:1197-209.

17. Jürgens G, Graudal NA. Effects of low sodium diet versus high sodium diet on blood pressure, renin, aldosterone, catecholamines, cholesterols, and triglyceride. Cochrane Database Syst Rev 2004;1:CD004022.

18. Dahl LK. Possible role of salt intake in the development of essential hypertension. In: Bock KD, Cotlier PT, editors. Essential Hypertension. Berlin: Springer Verlog; 1960. p. 53-6.

19. Reeta KL, Khullar M, Kashap M, Pandhi P, Uppal R. Effect of oral magnesium supplementation on blood pressure, platelet aggregation and calcium handling in deoxycortisterone acetate induced hypertention in rats. J Hypertens 2000;18:919-26.

20. Tobian L, Lange J, Ulm K, Wold L, Iwai J. Potassium reduces cerebral hemorrhage and death rate in hypertensive rats even when blood pressure is not lowered. Hypertension 1985;7:110-4.

21. Coerstein HC, Yusef S. Dysglycemia and rate of cardio vascular disease. Lancet 1996;347:946-50.

22. Labounty TM, Gomez MJ, Achenbach S, Al-Mallah M, Berman DS, Budoff MJ, et al.. Body mass index and the prevalence, severity, and risk of coronary artery disease: An international multicentre study of 13,874 patients. Eur Heart J Cardiovasc Imaging 2013;14:456-63.

23. Hoffner SM, Mykkanen LK, Laokso M. Insulin resistance, body fat distribution and sex hormones in men. Diabetes 1994;43:212-9.

24. Sowers JR. Modest weight gain and the development of diabetes: Another prospective ANN Intern Med 1995;122:548-9

25. Singaru D, Greco D, Scarpitla AM. Blood pressure insulin secretion and resistance in non-hypertensive obese female subject. Int J Obese 1995; 19:1610-3

26. Bakris GL, Weir MR, Sowers JR. Therapeutic challenges in obese diabetic patients with hypertension. Am J Med 1996;101:533-46.

27. Scala May C, Laparte R, Dorman J. Insulin dependent diabetes mellitus mortality: The risk of cigarette smoking. Circulation 1990; 82:37-43.

28. Fornage M, Amas CL, Kardia S. Variation in the region of ACE gene influences inter individuals differences in blood pressure levels in young white males. Circulation 1991;97:1773-9.

29. O’Donnell CJ, Partner KL, Larson MG. Evidence for association and genetic linkage of the ACE locus with hypertension and blood pressure in men but not in women in the Framingham heart study. Circulation 1998;97:1966-76.

30. Cerosola G, Cotlane S, D'Lgnato G. Sympathetic activity in borderline and established hypertension in the elderly. J Hypertens 1988;1:555-8.

31. Rosenman RH, Brand RJ, Schaltz RT. Multivariate predictions of coronary heart disease during the 8.5 years follow up in the western collaborative group study. Am J Cardiol 1976;37:903-12.

32. Davi G, Caltalons I, Averna M. Thromboxane biosynthesis and platelet function in Type II Diabetes Mellitus. N Eng J Med 1990;322:1768-74.

33. Goligorsky MS. Endothelial cell dysfuntion and nitric oxide synthase. Kidney Int 2000;58:1360-76.

34. Ramirez LC, Arauz-Pachaco C, Lackner C. Lipoprotien (a) levels in diabetes mellitus: Relation to metabolic control. Ann Intern Med 1992; 117:42-47.

35. Landing K, Born LT, Smith U, Elevated fibrinogen and plasminogen activator inhibitor (PAI-I)in hypertension are related to metabolic risk factors for cardiovascular disease. Intern Med 1990;227:273-8.

36. Boers GH, Tribels FJ, Fowler B. Heterozygosity for homocysteinuria in premature peripheral and cerebral occlusive arterial disease. $\mathrm{N}$ Engl $\mathrm{J}$ Med 1985;313:709-14.

37. Dluhy RG, Williams GH. Endocrine hypertension. In: Wilson JD, Foster DW, Kronenberg HM, editors. Williams Textbook of Endocrinology. $9^{\text {th }}$ ed. Philadelphia, PA: WB Saunders Publication; 1998. p. 729-49.

38. Kotchen TA. Hypertensive vascular disease. In: Longo D, Fauci A,
Kasper D, Hauser S, Jameson J, Loscalzo J, editors. Harrison's Principles of Internal Medicine. $18^{\text {th }}$ ed. Harvard: McGraw Hill Publication; 2011. p. 2042-59.

39. Conway J. Hemodynamic aspects of essential hypertension in humans. Physiol Rev 1984;64:617-60.

40. Navar LG. Counterpoint: Activation of the intrarenal renin-angiotensin system is the dominant contributor to systemic hypertension. J Appl Physiol 2010;109:1998-2000.

41. Ching N. Yellow Emperor's Classic of Internal Medicine. Books 2-9, Published between 2698 and 2598 B.C; 2006.

42. Korotkoff NS. Izvestiya Imperatorskoi Voenno-Meditsinskoy Akadernii. Rep Imper MIL Med Acca St Peterburg 1905;11:365-7.

43. Freis ED. In: Laragh JH, Brenner BM, editors. Hypertension, Pathophysiology Diagnosis and Management. $2^{\text {nd }}$ ed. New York: Raven Press; 1995. p. 2741-51.

44. Strickler CW. Significance of Hypertension. South Med J 1917;10:191-4.

45. White PD. Heart Disease. $2^{\text {nd }}$ ed. New York: MacMillan Co.; 1937. p. 326 .

46. Moser M. Evolution of the treatment of hypertension from the 1940 s to JNV V. Am J Hypertens 1997;10:2S-10S.

47. VA Cooperative Study Group. Effects of treatment on morbidity in hypertension Results in patients with diastolic blood pressures averaging 115 through 129 mm Hg. JAMA 1967;202:1028-34.

48. Hamdy RC. Hypertension: A turning point in the history of medicine and mankind. Southern Med J 2001;94:1045-47.

49. Report of the joint national committee on detection, evaluation, and treatment of high blood pressure. A cooperative study. JAMA 1977;237:255-61.

50. ALLHAT Officers and Coordinators for the ALLHAT Collaborative Research Group. The Antihypertensive and Lipid-Lowering Treatment to Prevent Heart Attack Trial. Major outcomes in high-risk hypertensive patients randomized to Angiotensin-converting enzyme inhibitor or calcium channel blocker vs diuretic: The antihypertensive and lipid-lowering treatment to prevent heart attack trial. JAMA 2002;288:2981-97.

51. Oparil S. High blood pressure in: Goldman L, Bennett JC, editors. Cecil Textbook of Medicine. Philadelphia, PA: WB Saunder; 2000. p. 718-20.

52. Sacks FM, Svetkey LP, Vollman WM, Appel LJ, Bray GA, Harsh D, et al.. Effects of blood pressure of reduced dietary $\mathrm{Na}$ and dietary approaches to stop hypertension (DASH) diet. N Engl J Med 2001;344:3-10.

53. Cook NR, Cohen J, Hebert PR. Implications of small reduction in diastolic blood pressure for primary prevention. Arch Intern Med 1995; $155: 701$.

54. Moser M. The sixth report of the Joint National Committee on prevention, detection, evaluation, and treatment of high blood pressure. Arch Intern Med 1997;157:2413-46.

55. Cobe MC, Bockarich MA, Srivastava K, Young DB. Potassium inhibits free radical formation. Hypertension 1994;24:77-82.

56. Sempos C, Copper R, Kovor MG. Dietary calcium and blood pressure in national health nutrition examination survey I and II. Hypertension 1986;18:1067-74.

57. McCorron DA. Calcium and magnesium nutrition in human hypertension. Ann Inter Med 1983;198:800-5

58. Trial of Hypertension Prevention Collaborative Research Group. Effect of weight loss and sodium reduction intervention on blood pressure and hypertension incidence in overweight people with high normal blood pressure. The trial of hypertension prevention, phase II. Arch Inter Med 1997; 157:657-67.

59. Cushman WC, Cutlar JA, Hanna E. The prevention and treatment of hypertension study (PATHS). Arch Intern Med 1998;158:1197-207.

60. Isles $\mathrm{C}$, Brown JJ, Ceimming AM. Excess smoking in malignant phase hypertension. BMJ 1979;1:579-81.

61. Rosenberg L, Kaufman DW, Helmrich SP, Shapiro S. The risk of myocardial infarction after quitting smoking in men under 55 years of age. N Engl J Med 1985;313:1511-4.

62. Blair S, Goodyear N, Gibbons L. Physical fitness and incidences of hypertension in healthy normotensive men and women. JAMA 1984;252:487-90.

63. Stapleton MP. Sir James Black and propranolol. The role of the basic sciences in the history of cardiovascular pharmacology. Texas Heart Inst J 1997;24:336-42.

64. Brogden RN, Heel RC, Speight TM, Avery GS. Metoprolol: A review of its pharmacological properties and therapeutic efficacy in hypertension and angina pectoris. Drugs 1977;14:321-48

65. Barreras A, Turner CG. Angiotensin II receptor blockers. Proc Baylor 
Univ Med Centre 2003;16:123-6.

66. Jackson TW, George B, Tom G, Larry YA, Lawrence JA, Jeanne C, et al. . Effect of blood pressure lowering and antihypertensive drug class on progression of hypertensive kidney disease. J Am Med Assoc 2002;288:2421-31.

67. Rasmussen S, Arnung K, Eskildsen PC, Nielsen PE. A comparative study of atenolol and Metoprolol in the treatment of hypertension. Br J Clin Pharmacol 1981;12:887-91.

68. Freytag F, Schelling A, Meinicke T, Deichsel G. Comparison of 26-week efficacy and tolerability of telmisartan and atenolol, in combination with hydrochlorothiazide as required, in the treatment of mild to moderate hypertension: A randomized, multicenter study. Clin Ther 2001;23:108-23.

69. Van Miegham W. A multicentre, double blind, efficacy, tolerability and safety study of the oral angiotensin II antagonist olmesartan medoximil versus atenolol in patients with mild to moderate essentialhypertension. J Hypertens 2001;19 Suppl 2:152.

70. Alcocer L, Fernández-Bonetti P, Campos E, Ruiz RO, Bahena J, de la Fuente JJ, et al.. Clinical efficacy and safety of telmisartan $80 \mathrm{mg}$ once daily vs. atenolol $50 \mathrm{mg}$ once daily in patients with mild-to-moderate hypertension. Int J Clin Pract Suppl. 2004;145:35-9.

71. Puchler K, Laeis P, Gunther A. Safety, Tolearability and Efficacy of New Oral Angiotensin II (AT 1) Receptor Antagonist Olmesartan Medoxomil with those of Atenolol in Patients with Moderate to Severe Hypertension under Continous Treatment with Hydrochlorothiazide;

72. Pollare T, Lithell H, Selinus I, Berne C. Sensitivity to insulin during treatment with atenolol and metoprolol: A randomised, double blind study of effects on carbohydrate and lipoprotein metabolism in hypertensive patients. Br Med J 1989;298:1152-7.

73. Sahana GN, Sarala N, Kumar TN, Lakshmaiah V. A comparative study of atenolol versus nebivolol on blood pressure and heart rate on essential hypertensive patients. Indian J Pharmacol 2010;42:401-5.

74. Fonseca VA. Effects of beta-blockers on glucose and lipid metabolism. Curr Med Res Opin 2010;26:615-29.

75. Smith J, Ferland A, Methot J, Brassard P, Lacroixs S, Poirier P, et al. The beta-1 adrenergic-antagonist, atenolol decreases acylation stimulating protein, exercise capacity and plasma free fatty acids in men with Type 2 diabetes. Nutr Metab Cardiovasc Dis 2012;22:495-502. 